\title{
La identidad al otro lado de la Cordillera: migración, identidad e integración
}

\author{
Identity on the Other Side of the Cordillera. Reflections on \\ Migration, Identity and Integration
}

\section{A identidade ao outro lado da Cordilheira. Reflexo em torno à migração identidade e integração}

\section{Florencia Jensen* - Argentina}

\author{
Recibido el 15 de abril de 2011, aceptado el 27 de marzo de 2012
}

\section{Resumen}

Objetivo: analizar las características principales del proceso de integración social y reconfiguración identitaria de la comunidad de migrantes recientes argentinos en la ciudad de Santiago de Chile. Metodología: se desarrolló con un enfoque cualitativo con entrevistas semiestructuradas lo que permitió interactuar con los protagonistas y acceder a través de su relato a las prácticas y percepciones de integración. Se utilizaron como categorías de análisis tres temas contemporáneos: la identidad como concepto; la identidad y su reconfiguración en un contexto migratorio concreto y la identidad y su vinculación con los procesos de integración en la sociedad de destino. Resultados: los migrantes argentinos llegan con altos niveles educativos, son incorporados a empleos formales y tienen acceso a bienes y servicios. No obstante, si bien la comunidad argentina es aceptada y valorada en el proceso de integración y asimilada en términos culturales, en el trayecto se produce una pérdida de la identidad cultural hasta llegar a lo que se podría denominar su "aculturación". El análisis de la dimensión sociocultural de la integración es la que permite observar los procesos de reconfiguración identitaria que opera en los migrantes argentinos. Se encontraron espacios de conflicto en el mantenimiento de la propia identidad al tiempo que se adoptaron determinados elementos de la cultura del país de acogida, y en este sentido operó la reconfiguración de la identidad. Conclusiones: la integración es percibida por los migrantes como conflictiva, donde lo que permanece es la aceptación de las reglas y normas del país de destino, lo cual actúa como un modelo de integración asimilacionista.

Palabras claves: migración, Chile, Argentina, identidad, integración, percepción.

* Magíster en Antropología y Desarrollo. Socióloga. Doctoranda en Ciencias Sociales. Investigadora del Instituto de Investigaciones Gino Germani (Argentina).mfjensen@sociales.uba.ar

El presente artículo es el resultado de diferentes trabajos de investigación y reflexión. Por un lado, se tomaron en cuenta algunos resultados de la tesis de maestría de la autora, "Donde fueras haz lo que vieras'. Migración e Integración en el Chile contemporáneo" (Universidad de Chile, 2009), en la que se trabajó principalmente sobre el proceso y la trayectoria de integración de los migrantes. Dicha investigación es más amplia y tomó también al colectivo peruano (otro de los colectivos

Para citar este artículo:
Jensen, F. (julio - diciembre 2012). La identidad al otro lado de la cordillera: migración, identidad e integración. Ánfora, 19 (33), 13-30. Universidad Autónoma de Manizales. ISSN 01216538. 


\section{Abstract}

Objective: To analyze the main features of social integration and identity reconfiguration of the recent migrant community from Argentina to Santiago de Chile. Method: The research was carried out using a qualitative approach conducted through semi-structured interviews, which allowed interaction with participants and access to narratives about their practices and perceptions of integration. The categories of analysis were three contemporary issues: identity as a concept, identity and reconfiguration in a particular context of migration, and identity and its relationship to the processes of integration into the host society. Results: Argentine immigrants arrive with high levels of education, are incorporated into formal employment, and have access to goods and services. However, although the community from Argentina is accepted, valued in the integration process, and assimilated in cultural terms, in this process there is a loss of cultural identity until they reach what is known as "acculturation." The analysis of the sociocultural dimension of integration is what allows us to observe the identity reconfiguration processes operating in the Argentine migrants. We found areas of conflict in maintaining their identity while the adoption of certain elements of the culture of the host country. In this respect, the identity reconfiguration was successful. Conclusions: Integration is perceived by migrants as conflictive, where what remains is the acceptance of the rules and regulations of the destination country, which acts as an assimilationist model of integration.

Keywords: migration, Chile, Argentina, identity, integration, perception.

\section{Resumo}

Objetivo: analisar as características principais do processo de integração social e reconfiguração identidade da comunidade de migrantes recentes argentinos na cidade de Santiago de Chile. Metodologia: desenvolveu se com um enfoque qualitativo com entrevista semi- estruturadas o com que permitiu interatuar com os protagonistas e aceder a través de seu relato às praticas e percepções de integração. Utilizaram se como categorias de analises três temas contemporâneos: a identidade como conceito; a identidade e sua configuração num contexto migratório concreto e a identidade e sua vinculação com os processos de integração na sociedade de destino. Resultados: Os migrantes argentinos chegam coma tos níveis educativos, são incorporados a empregos formais e têm acesso a bens e serviços. Não obstante, se bem a comunidade argentina é aceita e valorada no processo de integração e assimilada em términos culturais, no projeto se produz uma perdida da identidade cultural até chegar o que se poderia denominar sua "aculturação". O analise da dimensão sociocultural da integração é a que permite observar os processos de reconfiguração da identidade que opera nos migrantes argentinos. Encontraram se espaços de conflito na manutenção da própria identidade ao tempo que se adotaram determinados elementos da cultura do país de acolhida, e neste sentido operou a reconfiguração da identidade. Conclusões: a interação é percebida pelos migrantes como conflitiva, onde o que pertence é a aceitação das regras e normas do país de destino, o qual atua como um modelo de integração assimilacionista.

Palavras Chaves: migração Chile, Argentina, identidade integração, percepção.

más numerosos en Chile); sin embargo, este estudio se centra en los resultados anteriormente mencionados. Por otro lado, la autora continúa trabajando en su tesis de Doctorado con la comunidad de inmigrantes argentinos en Chile, particularmente en Santiago. Se trata, en parte, de una continuidad y profundización de la tesis de maestría, incorporándole a la investigación el análisis de las identidades y las reconfiguraciones identitarias. Finalmente, este artículo es también resultado de diferentes discusiones y reflexiones en el marco del Seminario Módulo Doctoral "Identidad e Identidades", a cargo de los profesores Dr. Felipe Arocena Armas y el Dr. Rafael Antolínez Camargo realizado octubre de 2010, en el marco de la Red de Cooperación Internacional "Nuevas Perspectivas en Teoría de la Cultura”, en la Universidad Santo Tomás; Bogotá, Colombia. Los planteamientos aquí expresados son directa responsabilidad de la autora.

Para

citar este artículo:
Jensen, F. (julio - diciembre 2012). La identidad al otro lado de la cordillera: migración, identidad e integración. Ánfora, 19 (33), 13-30. Universidad Autónoma de Manizales. ISSN 01216538. 


\section{Introducción}

Este artículo presenta las principales características del proceso de integración y reconfiguración identitaria de uno de los grupos migratorios más relevantes en Chile -en términos numéricos-: la comunidad argentina. El objetivo del trabajo es esbozar algunas reflexiones en torno a tres temas contemporáneos: la identidad como concepto; la identidad y su reconfiguración en un contexto migratorio concreto (la migración reciente a Chile) y la identidad y su vinculación con los procesos de integración en la sociedad de destino.

El caso de la migración argentina en Chile tiene una larga trayectoria. En efecto, es una de las migraciones latinoamericanas con mayor presencia en dicho país, con 19 años de residencia (Stefoni, 2007), y constituye una de las primeras mayorías de los grupos de migrantes. Presencia visible sobre todo en el sur del país, en la Patagonia, donde las fronteras son más difusas y el movimiento hacia ambos lados de la cordillera es parte de la vida cotidiana de las personas, por lo que la migración entre ambos países adquiere una significación de amistad y convivencia -aunque no exenta de conflictosrelativamente estable. Sin embargo, la migración reciente hacia Chile y sobre todo la que se produce después de la crisis económica, social y política en Argentina, ha sido poco abordada.

Así, este trabajo se propone contribuir a la comprensión del proceso de reconstrucción de las identidades socioculturales de los migrantes argentinos en Santiago de Chile, explorando la relación con el proceso de integración social de dichos migrantes en las sociedades receptoras.

\section{Migración(es), Identidad(es) e Integración: propuesta de análisis}

La movilidad de las personas por espacios geográficos ha estado presente en la historia de la humanidad, pero es en la actual etapa de desarrollo mundial -que se ha denominado globalización-, en la que la migración adquiere características globales. La globalización ha influido en todas las esferas de la vida social, en los modos de pensar, actuar y reflexionar. Hablar de globalización supone pensar en un término y un proceso moderno para describir los cambios en las sociedades y en la economía mundial, que resultan de la intensificación de intercambios -económicos, comunicacionales, de las tecnologías, de personas- sin precedentes en el mundo. La aceleración de los flujos de las comunicaciones, de dinero, de bienes, imágenes e ideas y de la movilidad de las personas a través de las fronteras nacionales e internacionales, en fin, de la intensificación de la interacción, vincula, de hecho $-\mathrm{y}$ potencialmente-, a individuos, organizaciones, países y culturas.

Pensar las migraciones en un contexto globalizado, es pensar que éstas también se han globalizado; precisamente, Castles y Miller (2004) llaman a esta época la Era de 
las Migraciones, pues la mayoría tiene alguna relación con el fenómeno migratorio, por ejemplo, algún familiar, conocido o amigo que emigró o inmigró a otra ciudad o país lejano. El fenómeno de la migración se construye colectivamente. En esta forma, la pregunta por quiénes son los migrantes remite a la construcción del "otro" en lo social, lo cultural y lo histórico. El migrante, el extranjero, el "otro" no tiene características propias o naturales, sino que les son asignadas.

Migrar, cruzar una frontera, constituye un acto donde se cruzan un sinfín de factores sociales. Llegar a un destino desconocido implica esfuerzos, más aún cuando se ha decidido que ese otro lugar será un lugar de residencia y cuando pocas veces o casi nunca se ha salido del lugar de residencia habitual. Llegar al destino implica "adaptarse”, implica conocerlo, conocer sus calles, sus gentes, sus códigos; implica encontrar una actividad, un trabajo, un nuevo hogar, personas qué conocer, amigos. ¿Qué sucede entonces con el migrante cuando llega? ¿cómo se produce esa llegada? ¿a quiénes recurre? ¿cómo se integra a la sociedad? O bien ¿Cómo lo integra la sociedad de destino? ¿qué relaciones establece? ¿cómo configura su nueva vida? Esta nueva situación ¿lo modifica? ¿en qué aspectos?

La migración implica un proceso de inserción e integración a un nuevo espacio socio-cultural y un proceso de reconfiguración de la identidad, tanto individual como colectiva. Como lo plantea Chambers

La migración implica un movimiento en el que tanto el lugar de partida y el punto de llegada no son inmutables ni seguros. Exige vivir en lenguas, historias, e identidades que están sometidas a una constante mutación. Siempre en tránsito, la promesa de una vuelta a casa (...) se vuelve imposible" (1995, p. 19).

Así, se observa que el fenómeno migratorio le imprimió una nueva impronta a la sociedad contemporánea y, en este sentido, la aceleración de los procesos de migración ha puesto a las sociedades frente a una amplia gama de diversidad cultural. Múltiples identidades se encuentran, coexisten, se acercan, se alejan, dialogan y disputan, todo ello no exento de conflicto ${ }^{1}$.

Es necesario hacer una digresión para aclarar que, en efecto, la diversidad cultural es preexistente a las migraciones. Cada país contiene en sí mismo diversidades múltiples: étnicas, religiosas, políticas, etc. Sin embargo, lo "novedoso" que trae aparejada la migración es la coexistencia de culturas que, si no fuera por la migración/globalización no entrarían en contacto. Presuponer que la globalización, y la migración "crearon" la diversidad cultural sería una falacia absoluta. Diversidad cultural existió siempre, pero a partir de la aceleración de los flujos migratorios se permite el encuentro que antes parecía tan lejano. Encuentros que, sin embargo, son gestionados por los Estados-Nación desde una determinada perspectiva que va desde la invisibilización y criminalización, hasta el reconocimiento del aporte económico, político y cultural que generan estas migraciones. Al mismo tiempo las propias sociedades se enfrentan a dicho fenómeno también de manera problemática, o más bien, la "aparición" de esta diversidad en sociedades pensadas y creadas históricamente como homogéneas, les representan un conflicto, un cuestionamiento a resolver.

Para citar este artículo:
Jensen, F. (julio - diciembre 2012). La identidad al otro lado de la cordillera: migración, identidad e integración. Ánfora, 19 (33), 13-30. Universidad Autónoma de Manizales. ISSN 01216538. 
Si bien el fenómeno de las migraciones ha sido bastante tratado en la literatura de las ciencias sociales de las últimas décadas, la falta de un criterio de general aceptación sobre lo que se entiende por "migración" ha propiciado no pocas inconsistencias en los objetivos de las investigaciones, así como en la interpretación, evaluación y comparación de sus resultados y en el acopio de conocimientos sustantivos para fines teóricos (Herrera 1994 y Herrera, 2006). En efecto, dichos autores señalan la falta de rigurosidad en las definiciones conceptuales, que provendría de cierto exceso de confianza de los investigadores.

Preguntas tales como ¿Qué es ser un migrante? ¿Qué tiempo ha de pasar para que un individuo sea considerado un migrante? ¿Cuándo se es un migrante temporal o migrante definitivo? ¿Qué tiempo ha de transcurrir para que se le ponga bajo una u otra categoría?, obligan respuestas en las que, según Tilly (2005; citado en Ribas, 2004), se evidencie la necesidad de establecer a las personas en domicilios fijos, donde puedan ser registrados, enumerados y por ende "vigilados": una persona sin domicilio le da problemas no sólo a la policía, a la burocracia, sino también al concepto mismo de migración. En este sentido, las consecuencias de un encuadre conceptual incorrecto para distinguir entre quién debe ser considerado migrante y quién no, puede tomar consecuencias "insospechadas". La definición misma, tomada en forma arbitraria, excluiría varios tipos de flujos o "cadenas" migratorias.

Resulta evidente que las sociedades contemporáneas son cada vez más diversas: múltiples identidades se encuentran, coexisten, se acercan, se alejan, dialogan, todo ello no exento de conflicto, claro está. En este contexto, la pregunta por la identidad adquiere relevancia, pues no siempre estuvo presente como lo está en el mundo contemporáneo. Diversos autores (Hall, Bauman, Chambers, Castells, Taylor, entre otros) plantean la "explosión" de la "problemática" de la(s) identidad(es) e intentan dar cuenta de estos procesos. En este contexto de diversidad cultural "pujante", las preguntas por el ¿quién soy? y/o ¿quiénes somos? han emergido fuertemente y, dado que se muestran impermeables a explicaciones habituales, se requieren nuevos análisis, estudios, explicaciones, conceptos, teorías, en fin, un corpus que permita la lectura de estos procesos no ya desde perspectivas esencialistas inamovibles.

En comunidades pre-históricas, la identidad no presentaba tanta relevancia dado que las relaciones entre el individuo y la sociedad estaban esquemáticamente definidas y prefijadas. Si bien algunos de esos roles sociales siguen estando definidos, la modernidad los complejizó y, en este sentido, perdieron su capacidad explicativa a priori. Esto supone un mundo lleno de incertidumbres, de pérdida de certezas y, por ende, de una nueva e incesante búsqueda para dar respuesta a esas preguntas. Bauman (1996) plantea que se piensa en la identidad cuando no se está seguro del lugar al que se pertenece: "identidad es un nombre dado a la búsqueda de salida de esa incertidumbre" (Bauman, 1996, p. 41). En las ciencias sociales existen numerosas discusiones en torno al concep-

Para citar este artículo:
Jensen, F. (julio - diciembre 2012). La identidad al otro lado de la cordillera: migración, identidad e integración. Ánfora, 19 (33), 13-30. Universidad Autónoma de Manizales. ISSN 01216538 . 
to de identidad, las mismas que van desde posturas en extremo esencialistas hasta las más constructivistas (Beheran, 2009).

Algunas posturas esencialistas proponen pensar la identidad como mero reflejo del listado de rasgos culturales objetivos compartidos, mientras que otras entienden la identidad como una expectativa que busca explicar lo que la gente hace o debiera hacer con base en quiénes son, o a qué cultura pertenecen (Juliano, 2007). Se trata de enfoques que prescriben prácticas fundamentadas en una identidad imputada y a un sentido de determinación fuerte (Brubaker y Cooper, 2002) o de correspondencia necesaria entre pertenencia y comportamiento. Para Grossberg (1996) las posturas esencialistas suponen que cualquier identidad tiene cierto contenido intrínseco y esencial, definido por un origen común, una estructura común de experiencia o ambas cosas a la vez; es decir, una identidad plenamente constituida, independiente y distintiva.

El "giro subjetivo de la cultura moderna", siguiendo a Taylor (1993), puso en el centro al hombre y con él la decisión de responder a las preguntas de "quién soy" o bien "quiénes somos". En este contexto aparecen nuevas formas de abordar la cuestión de la(s) identidad(es), y con ello los enfoques constructivistas. Resulta interesante la crítica que realiza Juliano (2007) al "estallido" de estas perspectivas o enfoques de la identidad y plantea que si bien éstos se han sofisticado, también se "han multiplicado al punto de convertirse en una moda que paulatinamente inscribe asertos de sentido común en la práctica antropológica en particular y en las ciencias sociales en general" (Juliano, 2007, p. 57). Desde el enfoque de este trabajo, se coincide con esta crítica, reconociendo, no obstante, que el giro constructivista resulta un importante avance para pensar las identidades contemporáneas en general y, en forma particular, las identidades en contextos migratorios. Este enfoque constructivista, plantea la identidad no ya bajo un prisma esencialista, sino de forma relacional y contingente. Este modelo niega la existencia de identidades auténticas y originarias basadas en un origen o experiencia universalmente compartidos y argumenta que las identidades son siempre relacionales e incompletas; están en permanente proceso de constitución (Grossberg, 1996). La identidad se constituye como tal, sólo en la medida en que se diferencia de otra. O bien como lo plantea Hall (1996), la identidad necesita lo que queda afuera, su exterior constitutivo, para consolidar el proceso. Esto implica que cualquier significado "positivo" de un término sólo puede construirse a través de la relación con el otro, la relación con lo que él no es, con lo que justamente le falta, con lo que se ha denominado, afuera constitutivo.

Hall (1996) prefiere el concepto de identificación al de identidad como un intento de rearticular las relaciones entre sujetos y prácticas discursivas. Entiende la identificación como una construcción, un proceso nunca terminado, y por tanto "proceso" 18 permanente, que no está determinado, en el sentido de que siempre es posible "per6538 . 
derlo", "sostenerlo" o "ganarlo". La identificación es siempre condicional, y por tanto contingente. Así, la identificación es entonces un proceso de articulación, una sutura, una sobredeterminación y no una subsunción. El concepto de identidad/identificación que propone Hall, no es por tanto esencialista sino estratégico y posicional. Las identidades nunca se unifican y, en los tiempos de la modernidad tardía, se presentan cada vez más fragmentadas y fracturadas, por lo que nunca son singulares, sino construidas de múltiples maneras a través de discursos, prácticas, posiciones diferentes, a menudo contradictorias y antagónicas. Precisamente, porque las identidades se construyen en el discurso y no fuera de él se deben considerar producidas en ámbitos históricos e institucionales específicos, en el interior de formaciones y prácticas discursivas, mediante estrategias enunciativas determinadas, por lo que resulta evidente plantear el juego de modalidades específicas de poder.

Lo contextual, lo histórico y lo espacial también es retomado por Dreher (2007) en tanto el sujeto construye su propia realidad utilizando el conocimiento socialmente legitimado e internalizado, pero dicha construcción subjetiva de la realidad tiene lugar en dependencia con las circunstancias socio-históricas específicas donde se desarrolla, tal como lo expresa Juliano (2007):

Los sujetos se articulan como tales a partir de un trabajo de identificación que opera suturando identidades personales y colectivas (para sí y para otros), pero no lo hacen simplemente como a ellos les place, pues su trabajo de articulación opera bajo circunstancias que ellos no han elegido (p. 59).

Para los intereses de este artículo, conciernen las perspectivas que analizan la identidad como una posición dentro de un entramado social de determinaciones e indeterminaciones que están en permanente desajuste (en exceso o en falta) respecto a cualquier intento de totalización y sutura (Arfuch, 2002) para abordar el estudio de caso; es decir, no plantear "la identidad" como algo cerrado y acabado, sino resaltar su carácter cambiante, plural y constituido en los procesos de lucha por el reconocimiento social. El proceso es siempre imperfecto e inacabado, son construcciones que, desde el presente, buscan recrear el pasado con vistas a un porvenir deseado (Bayardo, 2003).

No obstante, es interesante rescatar lo planteado acertadamente por Juliano (2007), porque si bien las identidades están en proceso de construcción permanente, contingentes e inacabadas, ello no implica que no muestren una cierta regularidad en la dispersión que opera, por los efectos que las sedimentaciones puedan llegar a inscribir en los sentidos y las prácticas sociales. Es decir, si bien las identidades pueden ser múltiples, contradictorias y abiertas porque siempre ese está siendo interpelado desde distintas posiciones como sujetos sociales, ello no implica que no se manifiesten como totalidad, esto es, que operen suturas que inscriben ciertos puntos de condensación.

Asimismo, en esta línea, Chambers (1995) realiza un importante aporte respecto de la identidad en el ámbito de migración que resulta interesante rescatar. En un contexto

Para citar este artículo:
Jensen, F. (julio - diciembre 2012). La identidad al otro lado de la cordillera: migración, identidad e integración. Ánfora, 19 (33), 13-30. Universidad Autónoma de Manizales. ISSN 01216538. 
de diversidad nunca antes visto como sucede actualmente, la identidad se construye siempre en movimiento, así las historias individuales y el sentido de pertenencia asumen una forma contingente, en tránsito, que no tiene meta ni final (Chambers, 1995, p. 46), al igual que la narrativa de la nación como la construcción de una...

(...) "comunidad imaginada"; el sentir de nuestras identidades es un trabajo de imaginación, una ficción, una historia específica significativa. Nos imaginamos íntegros, completos, poseedores de una identidad plena que no está ni abierta ni fragmentada. Nos imaginamos autores y no ya objeto de las narrativas que constituyen nuestras vidas. Es esta clausura imaginaria la que nos permite actuar (Chambers, p. 47).

Entre migración e identidad, y lo que supone su proceso de reconfiguración, cabe introducir el concepto de integración social, en tanto los migrantes llegan a un "destino" hasta entonces "desconocido". Así, la integración en un contexto migratorio es comprendida también como un proceso dinámico que no puede ser comprendida más que a la luz del conjunto de prácticas, procesos y experiencias que articulan la vida social de los migrantes. Es a partir de estos elementos que se reconocen las principales claves que configuran las formas de integración en la sociedad de acogida. De ahí que este trabajo se haya propuesto estudiar la integración a la sociedad de destino y el proceso de reconfiguración identitaria a partir del discurso y la percepción de los propios migrantes, para reflexionar sobre la perspectiva nativa, y a la vez combinar dichas percepciones con la perspectiva de integración desde lo estructural.

Se trata de procesos en los que conviven la diversidad y la heterogeneidad de expresiones y proyectos vitales, tanto de tipo laboral, social, político y también de procesos y experiencias marcadas por el cambio, por permanentes transformaciones que tienen como consecuencia la modificación de las prácticas y las estrategias para lograr los objetivos planteados en una contexto de migración. En estos procesos hay sujetos de carne y hueso, personas migrantes que en el camino de la migración realizan aprendizajes, intentan incorporar nuevos códigos culturales, ensayan proyectos de cambio y de mejoramiento de sus vidas, al mismo tiempo que crean y recrean cotidianamente su identidad cultural.

No es intención de este artículo plantear la integración de los migrantes como "buena" o "mala" integración, así como los problemas que surgen con la presencia de los migrantes tampoco pueden ser leídos en clave de las diferencias culturales, sino que hacen referencia directa a los problemas sociales generados por la distribución desigual de la riqueza, la inclusión y las políticas sociales que se adopten respecto a ello, tanto en la sociedad de destino como en la de origen. En rigor, cuando se habla de integración de los migrantes en los países receptores se está al mismo tiempo poniendo en cuestión la incapacidad que han tenido los países emisores para integrar a estos sujetos que terminan optando por la migración como un camino para el mejoramiento de sus vidas y las de sus familias.

Para citar este artículo:
Jensen, F. (julio - diciembre 2012). La identidad al otro lado de la cordillera: migración, identidad e integración. Ánfora, 19 (33), 13-30. Universidad Autónoma de Manizales. ISSN 01216538. 


\section{Metodología}

Para este estudio, la opción de un enfoque de carácter cualitativo resultó la mejor decisión, ya que responde a las necesidades planteadas en los objetivos. La elección de la perspectiva permitió interaccionar con los protagonistas, acceder a través de su relato a las prácticas y percepciones de integración, comprender cómo es el proceso migratorio desde que es concebido y entender a cabalidad las formas de integración social y las prácticas que elaboran y desarrollan en el nuevo contexto social y cultural.

El grupo poblacional en el que se aplicó este estudio se denominó “migración argentina reciente", que tiene 10 años de residencia, aproximadamente. El tipo de estudio que se pretendió fue de tipo exploratorio-descriptivo, ya que, como sugiere Hernández, permite "especificar las propiedades de las personas, grupos, comunidades o cualquier otro fenómeno que sea sometido a análisis" (1991, p. 60). Es decir, medir aspectos específicos relacionados con un fenómeno en particular. Para el caso de esta investigación, el fenómeno es la migración y la dimensión específica de las formas de reconfiguración de la identidad y su vinculación con las formas de integración social; descriptiva en tanto se identifican las formas y las prácticas de integración social de los migrantes por medio de sus propios relatos.

La técnica de recolección de información que se desplegó para la concreción de los objetivos propuestos, fue la entrevista en profundidad y semi-estructurada por ser la metodología adecuada para hacer aprehensible la subjetividad social y la experiencia humana. La entrevista como narración reconstructiva privilegia el modo en que los actores interpretan su participación en el espacio social, su propia existencia y la existencia de sus otros significativos. La entrevista en profundidad supone la realización de reiterados encuentros cara a cara entre el investigador y los informantes, a fin de comprender sus patrones de vida, sus visiones del mundo y poder, a partir de sus propias palabras, recoger la experiencia migratoria de éstos. Siguiendo a Taylor y Bogdan, las entrevistas en profundidad son

Encuentros dirigidos hacia la comprensión de las perspectivas que tienen los informantes respectos de sus vidas, sus experiencias y situaciones, tal como lo expresen con sus propias palabras, las entrevistas en profundidad siguen el modelo de la conversación entre iguales y no de un intercambio formal de preguntas y respuestas (1992).

Con base en ello, se considera que el hecho que la propia investigadora formara parte de la comunidad de migrantes, pudo colaborar a generar un espacio íntimo de conversación que pretende la entrevista en profundidad. En efecto, en algunos de los encuentros este hecho generó mayor confianza entre los entrevistados. Sin embargo, resulta importante destacar que en más de una ocasión, los entrevistados identificaron la investigadora con una ciudadana chilena. En dichas situaciones la entrevista siguió esos patrones, sin que se hiciera la aclaración correspondiente, ya que se comprendió 6538. 
que los entrevistados estaban ubicándola de acuerdo con sus percepciones y representaciones en una determinada posición social. Se entiende, empero, que esta instancia no se remite solamente a las palabras, a lo discursivo, sino que también incluye esta variedad de información no dicha, así como los gestos, los espacios, etc.

Finalmente la técnica de entrevista semi-estructurada se aplicó a nueve (9) migrantes de ambos sexos. Se consideró también el tiempo de residencia, pero sin tomar en cuenta el tipo de visado. Se tomaron casos de personas que han migrado a Chile en los últimos catorce (14) años. Las edades fluctuaron entre 20 y 45 años, y con diferente niveles de educación (básica, media y universitaria). La edad constituyó un elemento fundamental para observar las prácticas de integración y en este sentido el rango que se ha seleccionado habla de una migración que ha "decidido" la migración y que por tanto, permitió observar el proceso de integración en tanto interacción. Por último, se seleccionaron migrantes de diferentes niveles socioeconómicos y educativos por el interés de este estudio de abordar la integración diferenciada de los migrantes bajo el supuesto de que estas características inciden en esa integración diferenciada.

\section{Resultados}

Según el Censo 2002, la migración argentina en Chile presenta altos niveles de educación con un 56\% de migrantes con 10 años o más de estudios. Se trata de una migración urbana que se asienta principalmente en la ciudad de Santiago, se incorpora mayoritariamente a empleos formales, tiene mayor acceso a bienes y servicios que otros colectivos migratorios, como por ejemplo el peruano o boliviano. El comercio es una de las principales ramas de actividad donde se concentra la mayoría de la población argentina económicamente activa. Llama la atención que de los datos provenientes de la CASEN $2006^{1}$ se observa una alta presencia de migrantes mujeres -aproximadamente el 60\% de los migrantes argentinos son mujeres-, mientras que para el año 2002, los datos del Censo planteaban una relación 1 a 1 entre hombres y mujeres, lo que plantea la hipótesis de trabajo de que se estaría produciendo una segunda migración argentina (que bien podría pensarse como consecuencia de la crisis del 2001 en Argentina), que se inserta en todos los sectores de la estructura social chilena y se instala principalmente en las regiones centro, sobre todo, en ciudades como Santiago y Valparaíso y en el Sur, en la Región de la Araucanía.

La migración argentina hacia Chile, particularmente a la ciudad de Santiago, comienza a aumentar a mediados de los noventa cuando el desempleo en Argentina alcanza sus mayores índices, como consecuencia de la flexibilización del mercado laboral y de las políticas neoliberales, entre otros factores. Hacia fines de esa década ya se comienza a visibilizar el fin de una etapa, aumentan las protestas sociales y el descontento e integración. Ánfora, 19 (33), 13-30. Universidad Autónoma de Manizales. ISSN 01216538. 
generalizado de la población. Se observan -quizás por primera vez con tanta intensidad-imágenes que serían desoladoras: filas de personas en las puertas de los consulados de países como Italia y España, realizando los trámites para emigrar hacia aquellos países. Es decir, los nietos y bisnietos de aquellos primeros migrantes europeos del Siglo XX, ahora hacían el camino de regreso. En tanto sociedad, para Argentina esto constituyó un evidente impacto en su imaginario colectivo.

En diciembre de 2001, se produjo el fuerte estallido social que terminó con la destitución del entonces presidente de la nación, Fernando de la Rúa, con la posterior sucesión de presidentes, inestabilidad política, económica (devaluación del peso, corralito financiero, fuga de capitales), y social (protestas, asambleas populares, etc.). En este periodo de crisis empieza a crecer el número de argentinos y argentinas que ven a Chile como una posibilidad de salir, de "escapar". Pero, ¿por qué Chile como destino? Se plantea como un país que ha transcurrido con cierta madurez la transición democrática, estabilidad económica, pero al mismo tiempo por la cercanía tanto geográfica como de lenguaje, cultural, histórica; elementos que constituyen el conjunto de motivaciones para migrar.

El inmigrante una vez que llega a este país de destino se encuentra con un nuevo panorama que, lo obliga en parte -y le sugiere en otra- reconfigurar su identidad. Por ejemplo, si encuentra un nuevo trabajo ¿bajo qué reglas de conductas -implícitas y explícitas- se debe manejar ahora? ¿Cuáles son las normas que debe acatar? Se configura como un nuevo trabajador, ahora se trata de "trabajador inmigrante". Son las nuevas reglas del ámbito del empleo al que se incorpora que debe dilucidar y, aún más, incorporar a su yo, o mejor a su "nuevo yo".

Ahora, en un ámbito más privado el inmigrante conoce personas, le interesa entablar nuevas amistades. Sin embargo, en ese país ¿las amistades se establecen de igual manera que en su lugar de origen? ¿Qué cambia? ¿Qué permanece? ¿Cómo llega a leer esas situaciones? El inmigrante no sólo "trae" consigo su cultura y su identidad sino que ahora se encuentra en una nueva cultura, con nuevas identidades a las que debe reconocer y comprender. No sólo es un inmigrante, sino que debe lograr insertarse en el conjunto de reglas y normas explícitas y no explícitas de esta sociedad de acogida, lo que dependerá del grado de apertura y diálogo que permita dicha sociedad.

Una aproximación al caso de los migrantes argentinos en Chile, de acuerdo con diversos estudios consultados (OIM, 2004 y Stefoni, 2007) y el que actualmente realiza la autora, permite afirmar que la migración argentina en Chile no presenta mayores dificultades en el proceso de integración, la cual se produciría "sin mayores conflictos". Esta supuesta ausencia de conflictos, corresponde -a modo de hipótesis- a que históricamente la construcción del "otro" en Chile se ha realizado dentro de la dualidad superior/inferior, lo que supone que si se ubica al 'otro' en la segunda categoría se termina por marginarlo y excluirlo.

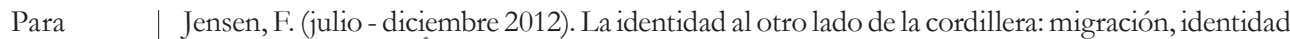
6538 . 
De acuerdo con esto, en el imaginario social en Chile la imagen de sí mismo se ha asociado más cercana al tipo europeo que al indígena, a tal punto de invisibilizar a las comunidades indígenas autóctonas y, más recientemente, a las comunidades de migrantes andinos (peruanos y bolivianos). En este sentido, al migrante argentino se lo asocia más al tipo europeo, por lo cual se le acepta, valora e integra sin conflicto.

Esto se puede verificar en los silencios y las ausencias en el discurso público respecto de la migración argentina. Tanto en los medios de comunicación como en los estudios realizados en torno a la "problemática" migratoria reciente en Chile, ésta se asocia en forma directa con los migrantes peruanos, bolivianos y paraguayos; sin embargo, poco se habla o se conoce de los migrantes argentinos en el país trasandino. Este tipo de migración es de cierta forma "invisible" aún cuando, tal como se ha mencionado, los argentinos superan numéricamente en Chile a otras comunidades de migrantes.

Como se dijo, los procesos de integración nunca son acabados, son procesos dinámicos, son formas de relación, es el encuentro entre heterogeneidades, entre alteridades que se configuran y reconfiguran constantemente. En este proyecto migratorio, en el que se aventuran estos sujetos de carne y hueso que son los migrantes, adquieren destrezas, habilidades que despliegan a lo largo de su vida como migrante. Para la mayoría de los migrantes argentinos, la integración económica se produce sin mayores inconvenientes. Esto, en parte, porque la comunidad argentina responde a la lógica estratificada de la sociedad chilena.

Los migrantes argentinos llegan con altos niveles educativos y en este sentido son incorporados a empleos formales y tienen mayor acceso a bienes y servicios. No obstante, si bien la comunidad argentina es aceptada y valorada en el proceso de integración y asimilada en términos culturales, en el trayecto se produce una especie de pérdida de la identidad cultural hasta llegar a lo que se podría denominar su "aculturación". El análisis de la dimensión sociocultural de la integración es la que permite observar los procesos de reconfiguración identitaria que opera en los migrantes argentinos. Los entrevistados reconocen que en el proceso de integración incorporan costumbres y hábitos del mundo social chileno, como pueden ser los modismos, las reglas sociales, las formas de acceso a diferentes ámbitos, o bien ciertos gustos culturales. Sin embargo, la expresión de la identidad nacional queda relegada al ámbito privado, lo que se traduce en una tensión y conflicto en el proceso de construcción de la identidad como migrante. Si bien existen similitudes entre ambos países y culturas que los entrevistados rescatan como positivo para poder insertarse en el país de destino, la percepción de los migrantes es que no existe espacio - en lo público- para el desarrollo de sus hábitos y costumbres originales.

Se advierte que al mismo tiempo que existen reivindicaciones en defensa de la identidad cultural propia, se acepten los modos de vida, las instituciones y símbolos de la sociedad de acogida; y en este sentido, el discurso de los migrantes es similar, independientemente de su posición en la estructura social. Los entrevistados plantean que

Para citar este artículo:
Jensen, F. (julio - diciembre 2012). La identidad al otro lado de la cordillera: migración, identidad e integración. Ánfora, 19 (33), 13-30. Universidad Autónoma de Manizales. ISSN 01216538 . 
la integración de las minorías debe estar supeditada a la mayoría y que, en definitiva, son los propios migrantes los responsables de "adaptarse" a la nueva realidad que los rodea. La percepción que la integración es sólo posible a partir de la adaptación, vía la asimilación a la sociedad mayoritaria y que no existe un verdadero diálogo, y ni mucho menos tolerancia hacia la diversidad, o mejor cierta diversidad.

"Sí, obviamente. Porque soy yo la que vengo de afuera. Yo soy la que me inserto en la sociedad. Entonces tengo que respetar cosas de la sociedad (Mujer joven).

Llegó un momento en que yo si quería, si yo quería me metía entre medio de todos los chilenos y pasaba por uno más, qué se yo" (Hombre joven).

En este sentido, se evidencia que los migrantes van dejando paulatinamente algunas actividades o costumbres propias de su cultura de origen, como se corrobora en este testimonio de un migrante:

"Antes yo era sólo, acompañado, como fuera, amargo, dulce, como viniera, tomaba todo el día, mate de té, de yerba, tereré, lo que fuera, me entendés? Ahora no, esa es otra de las cosas viste... pero yo veo que voy a Argentina a casa de mis viejos los fines de semana y estoy todo el fin de semana tomando mate...no lo perdí...es un tema de que me adapté a Chile me entendés, entonces no sé si está bien o está mal, yo me siento bien, yo me siento más cómodo así, no sé, que se yo, creo que está bueno..." (Hombre joven argentino).

Otro elemento que surge, lo constituyen las redes sociales interpersonales (amistades, parejas, relaciones de sociabilidad) como elemento relevante en la vida del migrante, y elemento particular en lo que refiere a la dimensión cultural de su integración. Se pueden identificar dos situaciones polarizadas respecto al establecimiento de redes de amistad con nacionales. Para un grupo de migrantes no resulta sencillo establecer lazos de confianza que operen como soporte y colaboren en la vida cotidiana de los sujetos, mientras que otro grupo manifiesta haber encontrado los mecanismos o espacios donde se pueden construir o establecer lazos de amistad.

El primer grupo aduce que existen determinadas características propias de los chilenos que finalmente dificultan el establecimiento de relaciones a largo plazo, como también influye la condición de ser extranjero que termina por marcar una diferencia y distancia entre nacionales y no nacionales.

Mi único problema acá en Chile es no encontrar personas, ya sea amigos, ya sea una pareja, cualquier tipo de relación, en que yo me pueda sentir en un nivel de confianza alto, importante, digamos (Hombre joven argentino).

Por el contrario, el otro grupo de migrantes expresan que han logrado establecer relaciones de amistad; sin embargo, se enfatiza que éstas no surgen del ámbito laboral, sino que se construyen a partir de otros espacios institucionales en los que se tiene interés común, por ejemplo, por una carrera, o el estudio de un idioma; es decir, excede el interés y la práctica laboral. Insertarse en esos espacios tiene sin duda un carácter 6538. 
instrumental en dos sentidos: la posibilidad de acumular capital cultural que engrose el currículum vitae $\mathrm{y}$, fundamentalmente, como un espacio de socialización.

En ambos casos, empero, resulta imprescindible contar con estos vínculos de amistad. Frente a situaciones de soledad, de extrañamiento, estas relaciones operan como un espacio de certeza y seguridad para los migrantes. En consecuencia, es más accesible establecer redes interpersonales y de amistad con migrantes de la misma nacionalidad, las que operan como soporte frente a situaciones de soledad o dificultades, o como un espacio para compartir tiempo y actividades de ocio, ligadas a la tradición nacional. Las prácticas se desarrollan principalmente en el tiempo libre, y se vinculan con la red que se construye con compatriotas, en un espacio de intimidad y confianza, con mayor o menor profundidad, intercambiando problemas e inquietudes respecto a su vida como migrantes.

Formé una muy linda amistad con Ariel, que es un compañero de acá, que es santafesino, que vive con su familia entonces por ejemplo paso allá, entonces es como sentirse un poco más en casa (Hombre joven argentino).

Te encontrás con un argentino en Chile, es como salen temas de conversación como qué hacés acá, cómo llegaste, que aquí que allá, que 'mirá tengo un asado el domingo que viene porque no te venís y conocés a mis amigos' y así se va encadenando todo eso, y vas conociendo más gente y eso es lindo... (Joven argentino).

Como se observa, contar con vínculos de amistad con compatriotas propicia la (re) configuración de la identidad nacional en un contexto de migración. En este sentido, los migrantes le otorgan significado a determinadas actividades y prácticas cotidianas que se relacionan con la reproducción de las características culturales propias, y en este proceso, no sólo "construyen al otro" con el que interactúan, al nacional, sino que también le otorgan significado a su propia nacionalidad.

Prácticas como un partido de fútbol, una comida, compartir música, intercambiar visiones sobre la situación actual del país de origen como el de acogida, se vuelven cotidianas.

Sí. Lo que pasa es que la casa de Ariel es casi otro centro argentino... tendrías que ver cuando juega Colón de Santa Fe como están todos ahí...arañan las paredes, o cuando corre el turismo carretera se llena de argentinos, es casi otro centro argentino. Tiene una parrilla enorme que se hizo atrás, hace unos asados espectaculares, entonces ese es como MI centro argentino propio, por ahí por eso no (Hombre joven argentino).

Así, se construye un adentro de un afuera, un aquí de un allá permanente, se delimitan los elementos aglutinadores de una identidad compartida, aquellos que siguen siendo ajenos. En este proceso se construye también al "otro" nacional en la medida en que le otorgan significado a un sí mismo, se alejan o se acercan del nacional, aquí aparece el mecanismo de la comparación como fuente de legitimación del proyecto 26 migratorio. e integración. Ánfora, 19 (33), 13-30. Universidad Autónoma de Manizales. ISSN 01216538. 
Se observó también que al mismo tiempo que existen espacios en los que se reivindica la identidad cultural propia, se aceptan los modos de vida, las instituciones y símbolos de la sociedad de acogida; el discurso de los migrantes es similar, independientemente de su posición en la estructura social. Un elemento que asoma a primera vista como consecuencia de la interacción cotidiana, y que los sujetos narran como una incorporación del nuevo entorno cultural, se refiere a palabras y modismos propios del lenguaje cotidiano chileno . En este sentido, las formas de hablar adquieren importancia y funcionan también como marca de diferenciación al incorporar los modismos locales, el habla y el acento opera difuminando la diferencia del "ser extranjero".

A la vez también el vocabulario, yo o sea, yo viví en puente alto, y en la villa portales, que son... que son complicado viste, o sea que son otra cultura dentro de las diferentes culturales que hay en santiago. Entonces me acostumbré muchísimo a los modismos, viste, 'no, estoy pal gato' risas o 'el cachai', me salía el 'cachai' a cada rato, y bueno, eh... (Hombre joven argentino).

La incorporación de los modos de hablar y de costumbres propias de la sociedad receptora forma parte del repertorio de prácticas en el proceso dinámico de integración de los migrantes. No se trata de un proceso acabado, ni mucho menos que a mayor cantidad de elementos incorporados de la cultura local mayor integración. Lejos está este estudio de presentarlo de tal forma. Es a partir del propio relato, de las narraciones de los migrantes, que emerge este elemento como constitutivo del proceso migratorio, un juego, un diálogo, un acercamiento a la vez que un alejamiento con la cultura de acogida.

\section{Conclusiones}

Los relatos muestran que emerge un espacio de conflicto en el mantenimiento de la propia identidad al tiempo que se adoptan determinados elementos de la cultura del país de acogida, y en este sentido opera la reconfiguración de la identidad. La integración es percibida por los migrantes como conflictiva, donde lo que debe permanecer es la aceptación de las reglas y normas del país de destino. En este sentido, surge un mecanismo normativo que plantea que son los propios migrantes los responsables de "adaptarse" a la nueva realidad que los rodea. Así la percepción de integración de los migrantes se acerca a una de las connotaciones que se ha generalizado y que dice relación con que la integración de los migrantes no debe plantear problemas a la sociedad mayoritaria. No se trata de una interacción de las prácticas de dos colectivos que entran en contacto, sino que más bien se acerca a la lógica de la asimilación cultural o la aculturación.

La pregunta que subyace aquí entonces es: ¿los discursos de los migrantes terminan por absorber y asimilar como propio lo que la sociedad mayoritaria plantea como discurso hegemónico de integración? Y en este sentido, ¿el único camino posible para la integración es a través de la aculturación o asimilación? Desde esta concepción, los migrantes suponen que el proceso de integración sociocultural implica adoptar,

Para citar este artículo:
Jensen, F. (julio - diciembre 2012). La identidad al otro lado de la cordillera: migración, identidad e integración. Ánfora, 19 (33), 13-30. Universidad Autónoma de Manizales. ISSN 01216538. 
consciente o inconscientemente, elementos de la cultura dominante, al tiempo que abandona ciertos rasgos de la identidad cultural de origen; es decir, se sigue la lógica de la asimilación cultural.

No obstante, el proceso no es tan lineal. En él se advierte la emergencia de contradicción y conflicto para los migrantes. Si bien por un lado se aceptan las condiciones que se establecen en la cultura chilena, los migrantes intentan mantener en el ámbito privado la identidad particular. Así, mientras en el contexto público se trata más bien de "adaptarse" "pasar desapercibido" "ser uno más", en términos personales se procura reproducir y reinterpretar los patrones culturales heredados de la propia cultura.

Los migrantes, con las tradiciones culturales que "traen" consigo y que articulan para desenvolverse en la sociedad de acogida, conducen a reconocer, como plantea Maffesoli (1990, p. 87), el irreprimible empuje de lo plural en las sociedades contemporáneas, un empuje que afecta ante todo a la teorización de lo "plural" (Santamaría, 2002 , p. 16). Es decir, la presencia de migrantes lleva irremediablemente a la presencia multicultural. como puede verse cada vez más en la ciudad de Santiago. Sin embargo, sería erróneo pensar que la sola presencia de diferentes culturas lleva al surgimiento de una sociedad multicultural. En efecto, no toda presencia multicultural lleva a un mayor diálogo, la convivencia pacífica, la tolerancia y el respeto.

La reproducción cultural no tiene porqué oponerse a una relación instrumental con la sociedad de acogida. Los migrantes deberían tomar aquellos elementos que le son significativos de la sociedad mayoritaria, sin ser sancionados ni por tal sociedad, ni por sus pares. A través de las entrevistas se ha observado que surge una variedad de prácticas y percepciones en torno a las relaciones, la interacción social y el sistema de referencia de la sociedad de acogida, por lo que, se puede sostener que mantener y reproducir tradiciones culturales en algunas esferas de la vida cotidiana no implica, necesariamente, generar actitudes o comportamiento de impermeabilidad cultural de la sociedad de acogida.

Se podría plantear, entonces, que una "positiva" integración en la sociedad de acogida es aquella que no exige necesariamente la disolución cultural, pérdida de identidad cultural, a la vez que se pueden producir mecanismo de identificación con algunos elementos de la sociedad de acogida. En este sentido, la interacción activa con la sociedad de acogida no tiene porqué ser contradictoria con el mantenimiento de las prácticas culturales de origen, ni tampoco poner a éstas en peligro: sin duda, todo un desafío, tanto para el Estado chileno, para la sociedad en su conjunto como para los propios migrantes.

Para $\quad$ Jensen, F. (julio - diciembre 2012). La identidad al otro lado de la cordillera: migración, identidad 


\section{Referencias}

Arfuch, L. (Comp.) (2002). Identidades, sujetos y subjetividades. Buenos Aires: Ed. Prometeo.

Bauman, Z. (1996). De peregrino a turista, o une breve historia de la identidad. En Hall, S. y Gay du P. (Comp.) (1996). Cuestiones de identidad cultural. Buenos Aires: Amorrortu.

Bayardo, R. (2003) Antropología, identidad y políticas culturales. Buenos Aires: Universidad de Buenos Aires.

Beheran, M. (2009). Migraciones y procesos identitarios en una escuela de la ciudad de Buenos Aires. VIII Reunión de Antropología del Mercosur, Diversidad y poder en América Latina, GT No 26: "Migraciones, identidades y conflictos", Buenos Aires, 29 de septiembre al 2 de octubre de 2009 .

Brubarker, R., y Cooper F. (2002) Más allá de la identidad. Apuntes de Investigación $\mathrm{N}^{\circ}$ 7, Buenos Aires.

Castells, M. (2000). El poder de la identidad en la era de la información. Madrid: Alianza.

Castles, S. y Miller, M. (2004). La era de la migración. Movimientos internacionales de población en el mundo moderno. México: Ed. Miguel Ángel Porrúa y Universidad Autónoma de Zacatecas.

Chambers, I. (1995). Migración, cultura, identidad. Argentina: Amorrortu.

Dreher, J. (Comp.) (2007). Construcción de identidades en sociedades pluralistas. Buenos Aires: Lumiere.

Grossberg, L. (2003). Identidades y estudios culturales ¿no hay más que eso? En Hall, S. y Gay du P. (Comp.) (1996), Cuestiones de identidad cultural. Buenos Aires: Amorrortu. Pp. 148-180.

Hall, S. (1996). ¿Quién necesita identidad? En Hall, S. y Gay du P. (Comp.) (1996), Cuestiones de identidad cultural. Buenos Aires: Amorrortu. (pp. 1-39).

Hernández, R. (1996) Metodología de la Investigación. México D.F.: Mc Graw Hill.

Herrera, E. (1994). Reflexiones en torno al concepto de integración en la sociología de la inmigración. Papers, Revista de Sociología (43). 71-76.

Herrera, R. (2006). La perspectiva teórica en el estudio de las migraciones. México: Siglo XXI.

Juliano, D. (2007) Teorías performativas y performatividad de las teorías. Tabula rasa, Universidad Colegio Mayor de Cundinamarca, Bogotá, (6), 53-83.

Maffesoli, M. (2004) El nomadismo. Vagabundeos iniciáticos. México: Fondo Cultura Económica.

OIM (2004). Estudio de caracterización sociodemográfica de la migración Argentina en Chile. Santiago de Chile: OIM Editorial.

Ribas, N. (2004). Una invitación a la sociología de las migraciones. Serie General Universitaria. (32). Barcelona: Bellaterra.

Santamaría, E. (2002). La incógnita del extraño: una aproximación a la significación sociológica de la 'inmigración no comunitaria'. Barcelona: Antrophos.

Para citar este artículo:
Jensen, F. (julio - diciembre 2012). La identidad al otro lado de la cordillera: migración, identidad e integración. Ánfora, 19 (33), 13-30. Universidad Autónoma de Manizales. ISSN 01216538. 
Stefoni, C. (2004). Inmigrantes Transnacionales. La formación de comunidades y la transformación en ciudadanos. Santiago de Chile: Ed. FLACSO.

Taylor, S. y Bogdan, R. (1992). Introducción a los métodos cualitativos de investigación. Barcelona: Paidós.

Taylor, Ch. (1993). El multiculturalismo y la política del reconocimiento. México: Fondo de Cultura Económica.

Tilly, C. (2005). Los movimientos sociales entran en el siglo XXI. Revista Política y Sociedad, 42 (2). 11-35.

Para $\quad$ Jensen, F. (julio - diciembre 2012). La identidad al otro lado de la cordillera: migración, identidad citar este e integración. Ánfora, 19 (33), 13-30. Universidad Autónoma de Manizales. ISSN 0121artículo: 6538. 